\title{
A Novel Nuclear Protein Interacts With the Symbiotic DMI3 Calcium- and Calmodulin- Dependent Protein Kinase of Medicago truncatula
}

\author{
Elsa Messinese, ${ }^{1,3}$ Jeong-Hwan Mun, ${ }^{2}$ Li Huey Yeun, ${ }^{1}$ Dhileepkumar Jayaraman, ${ }^{1}$ Pierre Rougé ${ }^{3}$ Annick \\ Barre, ${ }^{3}$ Géraldine Lougnon, ${ }^{1}$ Sebastian Schornack, ${ }^{4}$ Jean-Jacques Bono, ${ }^{3}$ Douglas R. Cook, ${ }^{2}$ and \\ Jean-Michel Ané ${ }^{1}$
}

${ }^{1}$ Department of Agronomy, University of Wisconsin, 1575 Linden Drive, Madison, WI 53706, U.S.A.; ${ }^{2}$ Department of Plant Pathology, University of California, One Shields Avenue, Davis, CA 95616, U.S.A.; ${ }^{3}$ Surfaces Cellulaires et Signalisation chez les Végétaux, UMR 5546 Centre National de la Recherche Scientifique-Université Paul Sabatier Toulouse III, F-31326 Castanet-Tolosan, France; ${ }^{4}$ Institute of Genetics, Martin-Luther-University Halle, Weinbergweg 10, 06108 Halle, Germany

Submitted 24 November 2006. Accepted 8 March 2007.

\begin{abstract}
Many higher plants establish symbiotic relationships with arbuscular mycorrhizal (AM) fungi that improve their ability to acquire nutrients from the soil. In addition to establishing AM symbiosis, legumes also enter into a nitrogen-fixing symbiosis with bacteria known as rhizobia that results in the formation of root nodules. Several genes involved in the perception and transduction of bacterial symbiotic signals named "Nod factors" have been cloned recently in model legumes through forward genetic approaches. Among them, DMI3 (Doesn't Make Infections 3) is a calcium- and calmodulin-dependent kinase required for the establishment of both nodulation and AM symbiosis. We have identified, by a yeast two-hybrid system, a novel protein interacting with DMI3 named IPD3 (Interacting Protein of DMI3). IPD3 is predicted to interact with DMI3 through a C-terminal coiled-coil domain. Chimeric IPD3::GFP is localized to the nucleus of transformed Medicago truncatula root cells, in which split yellow fluorescent protein assays suggest that IPD3 and DMI3 physically interact in Nicotiana benthamiana. Like DMI3, IPD3 is extremely well conserved among the angiosperms and is absent from Arabidopsis. Despite this high level of conservation, none of the homologous proteins have a demonstrated biological or biochemical function. This work provides the first evidence of the involvement of IPD3 in a nuclear interaction with DMI3.
\end{abstract}

Additional keywords: Lotus, NSP1, NSP2.

Plants are able to develop symbiotic associations with many microorganisms. The most economically and ecologically important beneficial interactions are those with arbuscular mycorrhizal (AM) fungi and nitrogen-fixing bacteria. Many

Elsa Messinese and Jeong-Hwan Mun contributed equally to this work.

Corresponding author: J. M. Ané; E-mail: jane@wisc.edu; Telephone: +1.608.262.6457; Fax: +1.608.262.5217.

The sequence data for IPD3 is available in the GenBank database under accession number EF117279.

* The $\boldsymbol{e}$-Xtra logo stands for "electronic extra" and indicates supplemental materials are published online. One additional table and three additional figures are available online. higher plants are able to form an association with AM fungi, resulting in increased access to otherwise limiting supplies of phosphorous, potassium, and nitrogen. AM-infected plants also acquire increased protection against various biotic and abiotic stresses (Harrier 2001; Newsham et al. 1995; Schützendübel and Polle 2002). In addition to AM symbiosis, legumes also enter into a nitrogen-fixing symbiosis with bacteria known as rhizobia. This symbiosis leads to the formation of a new organ, the root nodule. Specialized cells of the nodule central tissue contain endosymbiotic rhizobia, which trade fixed atmospheric nitrogen for a currency of plant photosynthates (Mylona et al. 1995).

An elegant combination of microbial genetics and biochemistry elucidated bacterial and plant factors that mediate the often-high level of host specificity observed in the rhizobialegume symbiosis. Legumes secrete an array of flavonoids and other secondary metabolites from their roots, certain of which activate the expression of bacterial nodulation (nod) genes. The nod gene products synthesize a lipochitooligosaccharide signal molecule, known as a "Nod factor," that activates a suite of symbiosis-related responses in compatible legume roots (Dénarié et al. 1996; Long 1996). A similar molecular dialog has been suggested to occur during AM symbiosis, with plants exuding strigolactones and fungi producing diffusible Myc factors (Akiyama et al. 2005; Kosuta et al. 2003). Recent studies have shown that Nod and Myc factors are both able to stimulate lateral root development, although the molecular nature of Myc factors remains unknown (Olah et al. 2005).

In recent years, forward genetic approaches in model legumes such as Medicago truncatula and Lotus japonicus have identified mutants affected in early responses to Nod factors (Oldroyd and Downie 2006; Riely et al. 2006b; Stacey et al. 2006). Phenotypic analyses of these mutants have placed the corresponding genes into a signaling cascade, and international efforts have led to the identification of these genes through map-based and transcript-based cloning. In M. truncatula, receptor-like kinases harboring LysM motifs in their extracellular domain reside at the top of this pathway and are putative Nod factor receptors that are predicted to span the plasma membrane (Arrighi et al. 2006; Limpens et al. 2003; Madsen et al. 2003; Mulder et al. 2006; Radutoiu et al. 2003; Spaink 2004). Another receptor-like kinase, known as DMI2, is known to localize to the plasma membrane and may transmit the Nod factor signal to a nuclear localized, putative ion channel named DMI1 (Ané et al. 2004; 
Endre et al. 2002; Imaizumi-Anraku et al. 2005; Limpens et al. 2005; Riely et al. 2007; Stracke et al. 2002). The DMI1 protein is required for the initiation of calcium spikes, which are regular oscillations in calcium levels within and around the nucleus. A calcium- and calmodulin-dependant protein kinase (CCaMK) named DMI3 plays a role downstream of the calcium spikes and is hypothesized to translate the calcium signal into one or more phosphorylation events (Lévy et al. 2004; Mitra et al. 2004). The activation of DMI3 leads to the transcription of symbiotic genes via plant-specific transcription factors, including two members of the GRAS family (NSP1 [Smit et al. 2005] and NSP2 [Kalo et al. 2005]) and an AP2-domain protein (Giles Oldroyd personal communication). In addition to promoting downstream gene expression, DMI3 negatively regulates upstream signaling events, as dmi3 mutants show an increased sensitivity for calcium spiking in response to Nod factors (Oldroyd et al. 2001). All dmi genes are required for AM symbiosis, demonstrating that the signaling pathways of nodulation and AM share common components (Riely et al. 2006).

DMI3 is a plant-specific protein, with only single copy identified to date in well-characterized plant genomes from the moss Physcomitrella patens to higher plants. The widespread distribution and high level of sequence conservation of DMI3 suggest a very ancient origin of this protein, which fits well with its proposed ancient role in AM symbiosis (Godfroy et al. 2006). Interestingly, no CCaMK has been identified in the Arabidopsis thaliana genome, suggesting that the lack of this protein is one reason for the inability of Arabidopsis to establish a mycorrhizal symbiosis (Zhu et al. 2006). In M. truncatula, strong expression of DMI3 has been detected in roots and nodules. Recent studies in M. truncatula and L. japonicus have shown that the absence of the calcium- and calmodulin-binding domains as well as a point mutation in the autophosphorylation domain of DMI3 lead to constitutive activation of the kinase domain, with consequent expression of nodulation genes and the development of spontaneous nodules in the absence of rhizobia (Gleason et al. 2006; Tirichine et al. 2006). Despite the central importance of DMI3 in the symbiotic signaling pathway, the nature of downstream phosphorylation targets and interacting proteins for DMI3 remain unknown.

Forward genetics has been extremely fruitful for the study of symbiotic signaling in legumes, and the almost complete overlap in genes identified in M. truncatula and L. japonicus suggests that the current mutant screens may be approaching saturation for easily-identified alleles. However, because forward genetics is limited in its ability to identify genes that make incremental contributions to phenotypes or to discover genes with essential or redundant functions, it is likely that additional genes remain to be identified. As an alternative to the genetic approach, the yeast two-hybrid (Y2H) system approach can be used to identify components of the Nod factor signaling pathway based on their physical interaction with target proteins such as DMI3. For example, a Y2H approach with the DMI3 CCaMK and using immature lily anthers was successful in identifying a homolog of eukaryotic elongation factor $1 \alpha$ (Wang and Poovaiah 1999), although the biological role of this interaction remains unknown.

In the present work using the $\mathrm{Y} 2 \mathrm{H}$ approach, we identified a novel protein named IPD3 (Interacting Protein of DMI3), which, like DMI3, belongs to a plant-specific family of genes present throughout the angiosperms but absent in Arabidopsis. Although IPD3 lacks homology to functionally characterized proteins, IPD3 is localized to the nucleus and contains a coiled-coil domain that may facilitate interaction with DMI3. We conclude that IPD3 is a new player in the symbiotic signaling pathway. Possible roles in nodulation and arbuscular mycorrhization are discussed.

\section{RESULTS}

Screening of M. truncatula Y2H libraries with the DMI3 protein.

The DMI3 protein of $M$. truncatula ecotype Jemalong (A17) was cloned into pBD-GAL4 yeast expression vector as bait in a Y2H screen. Two prey libraries were constructed from $M$. truncatula roots. The first prey library, MtY2H1, contained cDNA from roots of ecotype Jemalong A17 at $0,2,5$, and 10 days after inoculation with Sinorhizobium meliloti, while the second prey library, MtY2H2, contained equally pooled cDNAs of sunn and skl supernodulation mutants (Penmetsa and Cook 1997; Penmetsa et al. 2003) that were sampled at the same developmental timepoints as for MtY2H1.

MtY2H1 and MtY2H2 were screened with DMI3 as bait under stringent conditions. The bait and prey vectors were then transformed into yeast strain AH109 according to Clontech MATCHMAKER system 3's instructions, and the yeast colonies were grown on synthetic dropout medium lacking leucine, tryptophan, and histidine (SD Leu- Trp- His-) medium. Growth on this medium indicates activation of reporter genes and probable protein interaction. During two independent screenings of each library, two million transformants were screened and 18 clones were found to be Hist. Seven of these were able to grow on the more stringent SD Leu- Trp- His- adenine (Ade)- medium. After plasmids rescue from the His+ Ade+ clones, the cDNA inserted into pAD-GAL4 vector was analyzed by sequencing. All seven clones contained a pAD-GAL4 vector, with a cDNA coding the C-terminal region of a gene that we named IPD3 (Supplementary Table 1). To validate the interaction between DMI3 and IPD3, pAD-GAL4::(3')IPD3, rescued from one of the positives clones, was transformed into AH109 with pBDGAL4::DMI3. After 5 days, cotransformants were again able to grow on SD Leu- Trp- His-Ade- medium (Fig. 1).

RACE PCR (5' rapid amplification of cDNA ends polymerase chain reaction) allowed the identification of the 1,542-bp fulllength IPD3 coding sequence (CDS). The genomic sequence of IPD3 was determined by sequencing of the MtH2_33K20 bacterial artificial chromosome (BAC) clone selected by PCR

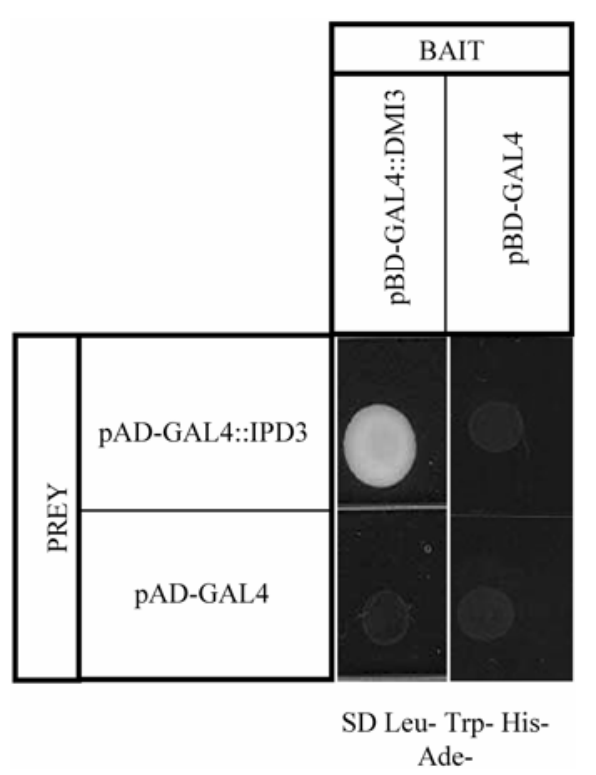

Fig. 1. Pairwise interaction between DMI3 and IPD3 in the yeast two-hybrid $(\mathrm{Y} 2 \mathrm{H})$ system. pAD-GAL4 and pBD-GAL4 are $\mathrm{Y} 2 \mathrm{H}$ vectors without any insert. Pairwise assays confirm the interaction between the $3^{\prime}$ region of IPD3 cloned into pBD-GAL4 and DMI3 in pAD-GAL4. No interaction was identified between pBD-GAL4::DMI3 and pAD-GAL4 constructs or between pBD-GAL4 and pAD-GAL4::IPD3. 
screening of the MtH2 BAC library (Mun et al. 2006). The IPD3 gene, which has a length of 3,835 bp and is divided into 11 exons, was genetically mapped to the short arm of chromosome 5 between markers MtB93 and MtB108 (Supplementary Fig. 1).

\section{Structural features of the IPD3 protein and conservation among the angiosperms.}

The IPD3 gene encodes a predicted protein of approximately $58 \mathrm{kDa}$ and an isoelectric point (pI) of 5.4. The HCA (hydro- phobic cluster analysis) plot of IPD3 suggests a complex $\alpha \beta$ structure with $\alpha$-helical structures predominantly located at both extremities (stretches from 1 to 130 and 380 to 513) of the polypeptide chain as summarized in Figure 2A. The N-terminal region of IPD3 lacks even moderate similarity to functionally characterized protein subdomains, whereas the C-terminus is predicted by MyHit protein motif search to contain an IMP dehydrogenase and GMP reductase domain with moderate probability. The most striking functional features of IPD3 are the

A

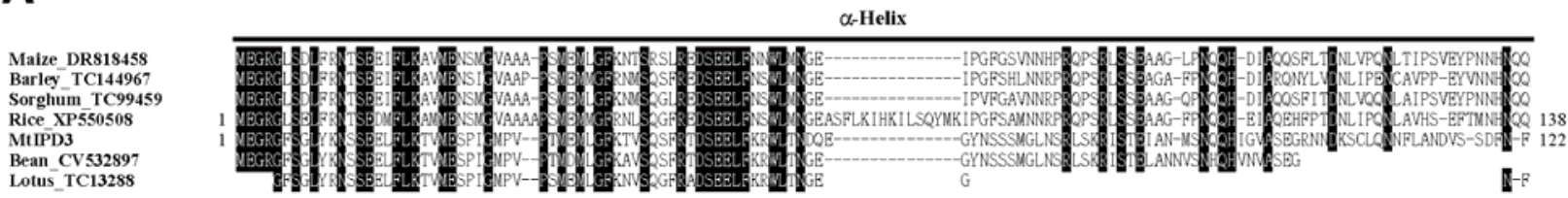

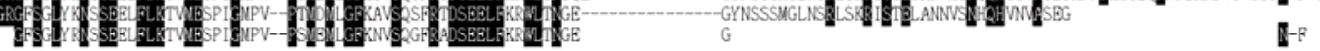

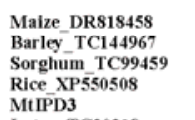

MtIPD3

Lotus_TC20218
Soybean BG239476
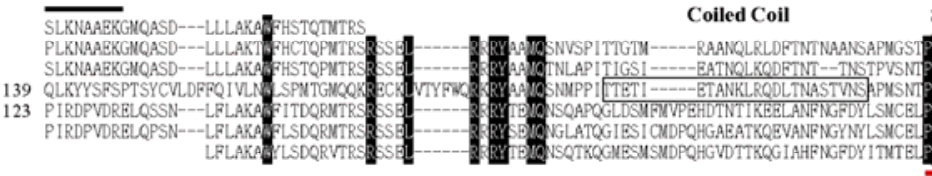

Ser/Thr-Rich Region

Coiled Coil

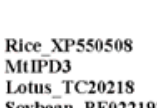

Coiled Coil

Ser/Thr-Rich Region

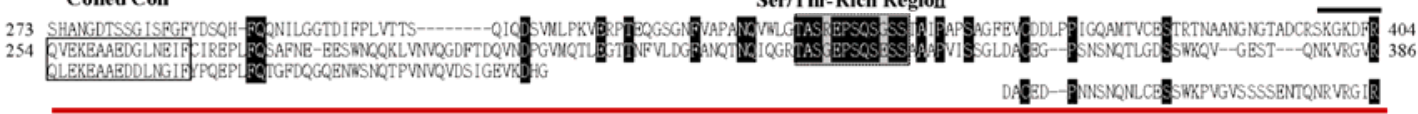

Soybean_BE022193

Maize TC284153

Rice_XP550508

MtIPD3

Lotus_TC11021

Soybean_BE022193

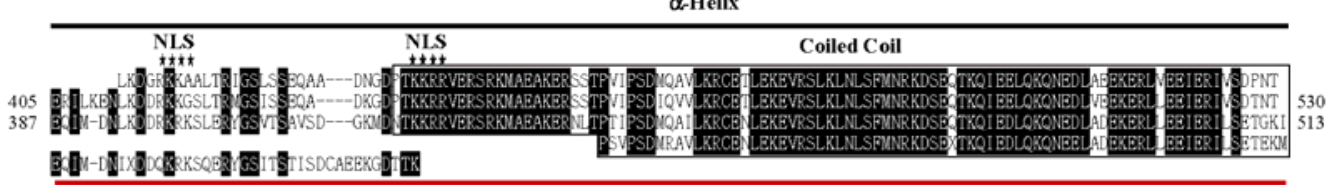

B
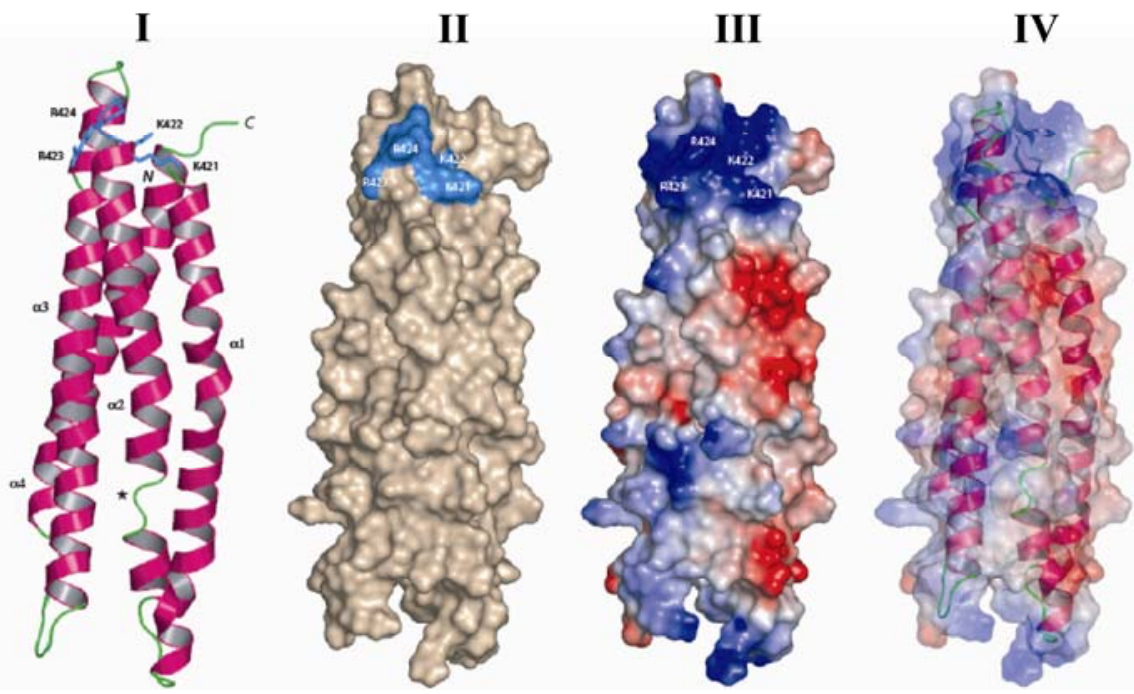

Fig. 2. Multiple alignments of IPD3 protein homologs and molecular modeling of the coiled-coil domain in IPD3 C-terminal region. Multiple alignments of IPD3 protein homologs and a model structure of coiled-coil domain in IPD3 C-terminal region. A, Alignment of full-length IPD3 and rice ortholog (XP550508) proteins with independent partial homologous sequences from maize (DR818458, TC284153), barley (TC144967), sorghum (TC99459), Lotus japonicus (TC13288, TC20218, TC20218), bean (CV532897), and soybean (BE022193, BE022193) by means of ClustalW. The conserved serine and threonine-rich regions are indicated in gray boxes. The structural domains predicted as coiled-coil structures are boxed in solid boxes whereas conserved nuclear localization signal (NLS) segments are indicated by asterisks. Predominant $\alpha$-helix structures in IPD3 predicted by hydrophobic cluster analysis plot are indicated by solid black lines. A red line indicates the region of IPD3 sufficient for interaction with DMI3. B, Homology modeling of the C-terminal coiled-coil structure of IPD3. I, Ribbon diagram of the C-terminal domain of IPD3 showing the overall coiled-coil organization made of four $\alpha$-helices ( $\alpha 1$ to $\alpha 4)$. $N$ and $C$ correspond to the N-and C-terminal ends of the domain, respectively. Residues forming the second 421KKRR424 NLS are in labeled blue ball-and-sticks. II, Molecular surface of the C-terminal domain showing the exposition to the solvent of the 421KKRR424 NLS (colored blue). III, Mapping of the electrostatic potentials on the molecular surface of the C-terminal domain showing the strong electropositive character of the 421KKRR424 NLS area. Electropositively and electronegatively charged surfaces are colored blue and red, respectively. Neutral surfaces are colored white. IV, Same representation as in III showing the ribbon diagram in transparency. 
presence of i) two serine- and threonine-rich regions (stretches from 208 to 226 and 331 to 443 ) that are potential sites of phosphorylation, and ii) two putative nuclear localization signals (NLS) (397RKRK400 and 421KKRR424) within the C-terminal end of the polypeptide. Eight putative $N$-glycosylation sites, distributed along the polypeptide sequence, occur in apparently well-exposed areas of the protein and are potential sites of glycosylation. Using the EMBnet coil server, two coiled-coil structures were predicted to occur in the middle (stretch from 244 to 267) and at the end (419 to 513) of the IPD3 sequence (Fig. 2B). The modeled C-terminal domain of IPD3 exhibits a canonical coiled-coil structure composed of four $\alpha$-helices connected by short loop segments (Fig. 2B, I), although helix $\alpha 2$ is interrupted by a short segment of coil structure. The first potential NLS (397RKRK400) is located in the middle of the C-terminal domain but is predicted to be inaccessible to the solvent (Fig. 2B, II) and, thus, may be poorly functional. In contrast, the second predicted NLS segment (421KKRR424) forms a positively charged patch that is predicted to be fully exposed on the surface of the C-terminal domain, consistent with a functional NLS (Fig. 2B, III and IV).

IPD3 homologs have been identified in both monocots and eudicots, including rice, barley, sorghum, maize, L. japonicus, soybean, and bean (Fig. 2A). Interestingly, Arabidopsis appears to lack an IPD3 homolog, revealing a taxonomic distribution similar to that of DMI3 among land plants (Lévy et al. 2004; Zhu et al. 2006). A rice homolog of IPD3 (XP_550508) possesses $>40 \%$ global identity and up to $81 \%$ identity in the Cterminus. However, the rice protein differs from its $M$. truncatula counterpart based on the number and location of the putative $\mathrm{N}$-glycosylation sites and the occurrence of only a single putative NLS in the C-terminal coiled-coil domain.

\section{IPD3 and DMI3 are coexpressed in roots and nodules.}

In silico analyses of expressed sequence tag (EST) frequencies in the $M$. truncatula GeneIndex suggests that IPD3 expression is specific to roots and root nodules. To test this prediction, transcripts of IPD3 and DMI3 were analyzed by
A

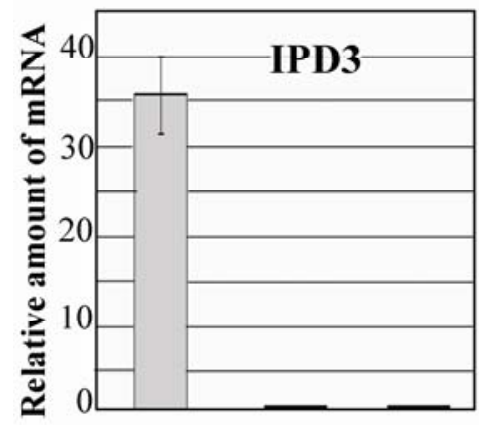

Roots Leaves Flowers
B

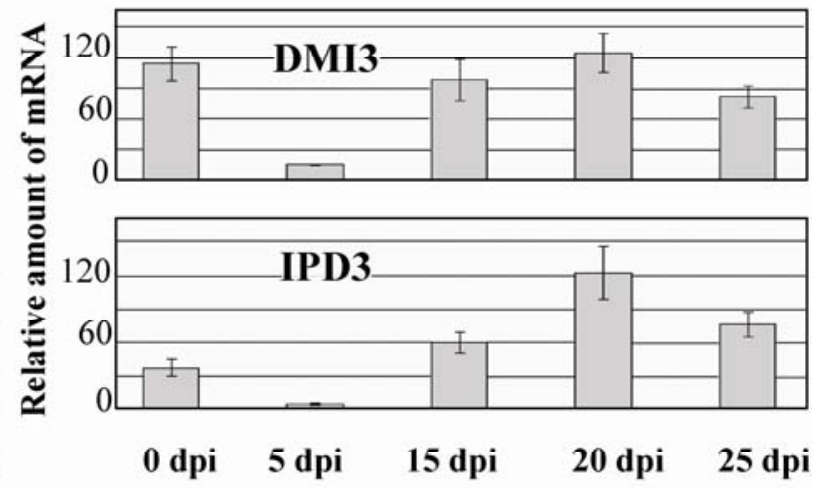

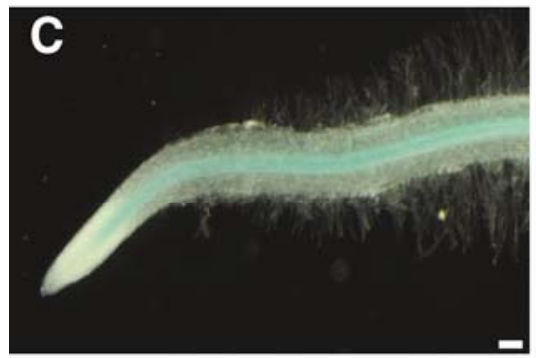
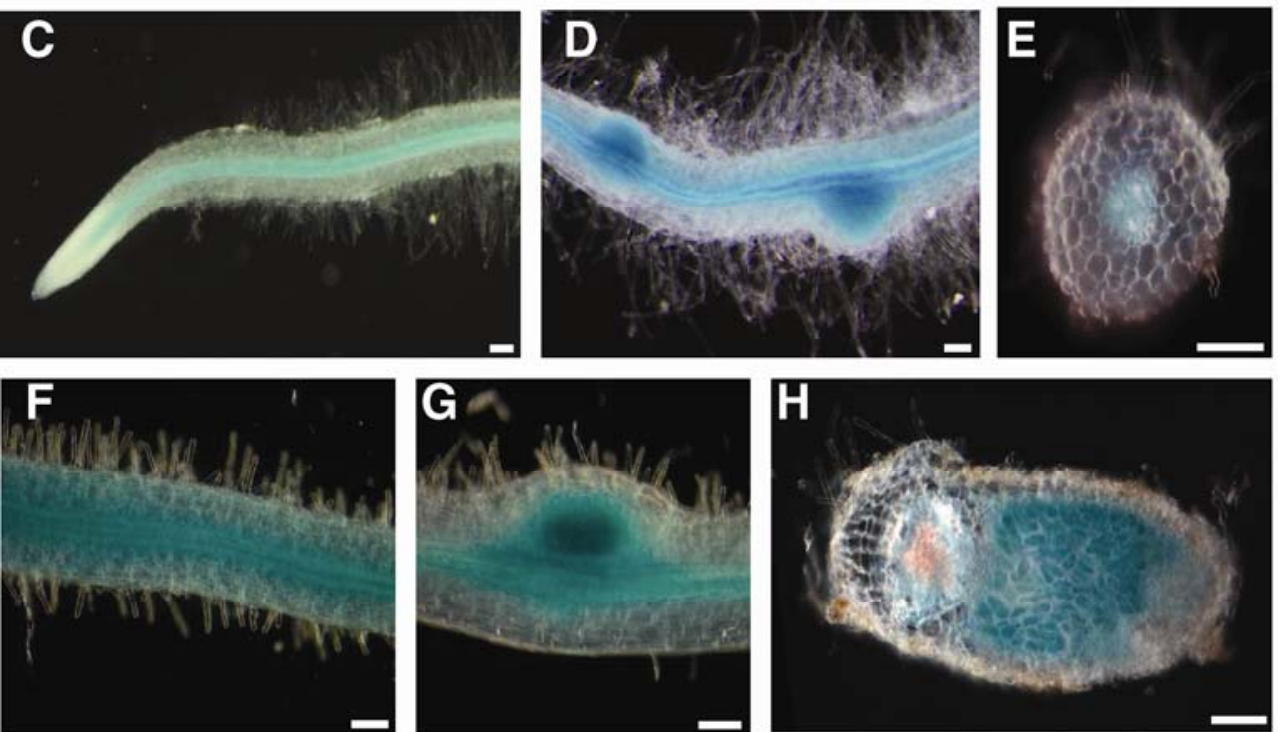

Fig. 3. Synchronous expression of DMI3 and IPD3 in Medicago truncatula roots. Relative transcript levels were determined by real-time quantitative reverse transcription-polymerase chain reaction and were normalized using MtACTIN2 as reference. A, Expression of IPD3 in various organs of wild-type plants. Roots are not inoculated with Sinorhizobium meliloti. B, Expression profiles of DMI3 and IPD3 in M. truncatula wild-type roots before and at 5, 15, 20, and 25 days postinoculation with $S$. meliloti. $\mathbf{C}$, through $\mathbf{E}$, Histochemical analysis of pIPD $3:$ GUS expression in transgenic roots of $M$. truncatula in the absence of $S$. meliloti. C, Primary root showing $\beta$-glucuronidase (GUS) expression in vascular bundle. D, Lateral root primordia, developing from the primary root, showing GUS staining in central cells. E, A $120-\mu \mathrm{m}$-thick cross section of primary root showing GUS expression mainly in phloem and pith of vascular bundle. F, through $\mathbf{H}$, Transgenic roots or nodules after inoculation of $S$. meliloti. F, Primary roots at 3 days after inoculation, showing induction of GUS expression in the cortex. G, Developing nodule in primary root at 5 days after inoculation showing GUS expression reduced in cortex but induced in the central, undifferentiated tissues of nodule. H, A 100- $\mu \mathrm{m}$ thick longitudinal section of mature nodule at $10 \mathrm{~s}$ after inoculation, showing strong GUS expression in the nitrogen fixation zone. Nontransgenic roots showed no GUS coloration (data not shown). Scale bars represent $500 \mu \mathrm{m}$. 
means of quantitative real-time PCR. As shown in Figure 3A, $I P D 3$ is strongly expressed in roots as compared with leaves and flowers. After inoculation with the rhizobial symbiont, IPD3 exhibits an expression pattern very similar to that of $D M I 3$, with a transient decrease in expression between 0 and 5 days postinoculation (dpi), returning to its original level by 15 dpi (Fig. 3B). In the absence of rhizobia or AM fungi, no statistically significant variation in IPD3 transcript levels was observed between wild type, $n f p, d m i 2, d m i 3$, and sunn mutant roots (Supplementary Fig. 3).

To characterize tissue-level activation of IPD3 promoter in roots and nodules, a 1.1-kbp genomic DNA fragment upstream of the translation start site was fused to the $\beta$-glucuronidase $(G U S)$ reporter gene. $35 S:: D s R E D 1::$ oct, cloned in cis to the IPD3::GUS fusion, served as a visual marker to identify transformed roots. Two weeks after transformation of Jemalong A17 with Agrobacterium rhizogenes, the distribution of GUS activity was assessed by histochemical staining and microscopy of sectioned or whole-mount specimens.

In the absence of rhizobial inoculation, pIPD3::GUS expression was mainly observed in the vascular tissue of roots, particularly in the phloem and pith, along with weak expression in the root inner cortex (Fig. 3C through E). Strong expression was also associated with sites of lateral root emergence (Fig. 3D). GUS activity was not detected in root apices (Fig. 3C), suggesting that expression at sites of lateral root formation was not simply a reflection of IPD3 promoter activation within root meristems. Inoculation of transgenic roots with $S$. meliloti was correlated with a significant change to the pattern of pIPD3::GUS expression. At $3 \mathrm{dpi}$, the IPD3 promoter was induced throughout the root cortex (Fig. 3F), while expression was maximal in nascent nodules assayed at 5 dpi (Fig. 3G). pIPD3::GUS expression in functional nodules 10 dpi was strongest from the region immediately proximal to the nodule meristem and extending throughout the nodule central tissue. Lower levels of expression were evident in the nodule meristem and in the main root vasculature (Fig. 3H).

\section{IPD3::GFP fusion localizes to the nucleus.}

The subcellular localization of an IPD3::GFP fusion protein was tested following stable transformation of $M$. truncatula roots with A. rhizogenes and transient transformation of Nicotiana benthamiana by means of Agrobacterium infiltration. IPD3::GFP expression was driven by the cauliflower mosaic virus $35 \mathrm{~S}$ promoter using the pK7FWG2 binary vector, while the control consisted of the pRedRoot::GFP binary vector expressing native green fluorescent protein (GFP) under the control of the 35S promoter (Riely et al. 2007). As shown in Figure 4B, $N$. benthamiana leaves expressing the control 35S::GFP exhibited strong fluorescence both in the cytoplasmic and nuclear compartments. Nuclear location was confirmed by means of $4^{\prime}, 6^{\prime}$-diamidino-2-phenylindole (DAPI) staining for DNA
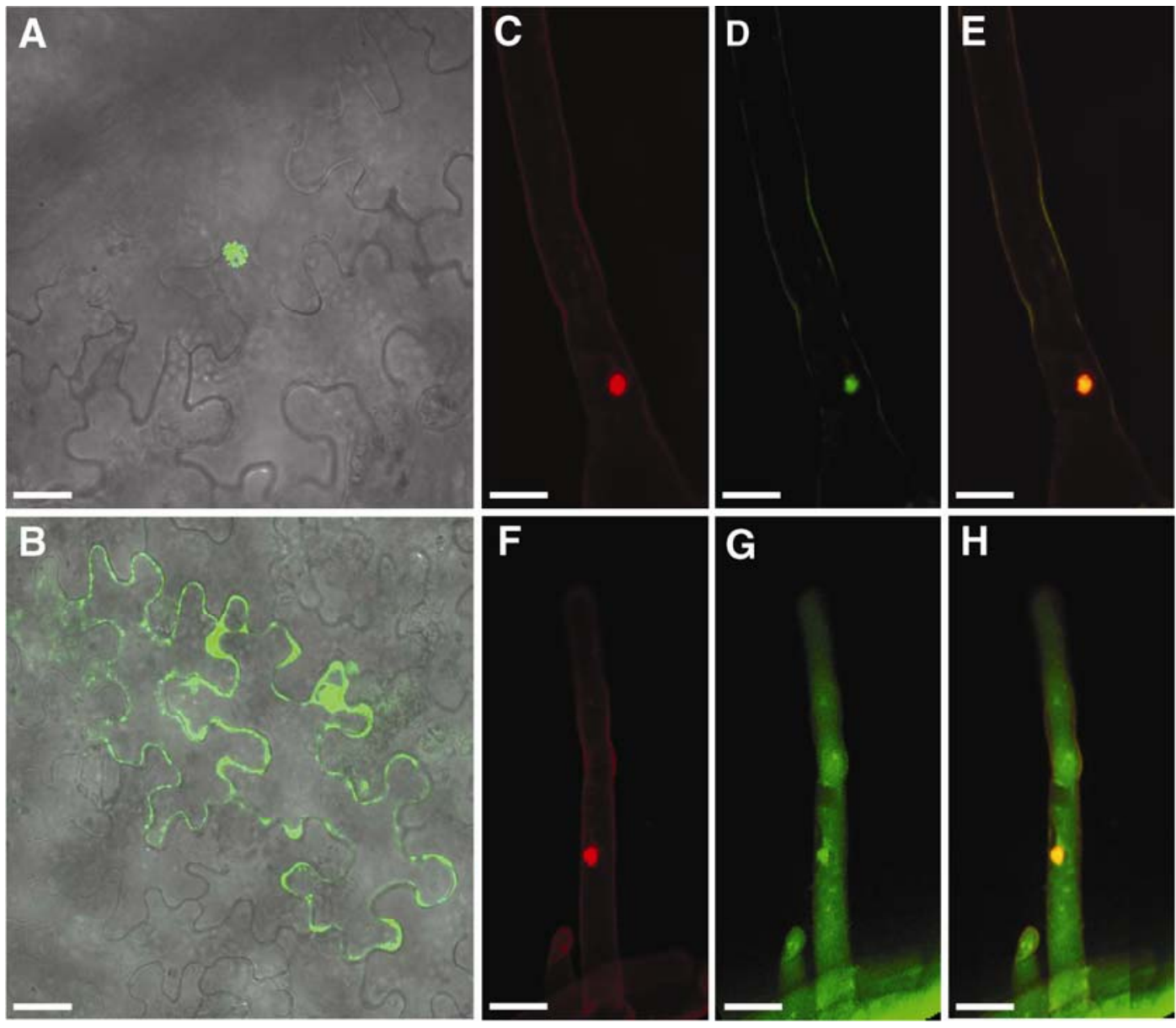

Fig. 4. Nuclear localization of IPD3 in Nicotiana benthamiana and Medicago truncatula cells. A, and B, IPD3::GFP localization in N. benthamiana. A, Nuclear localization of the IPD3::GFP fusion under control of the $35 \mathrm{~S}$ promoter in epidermal cells. A 4',6'-diamidino-2-phenylindole staining of $N$. benthamiana confirmed the nuclear origin of this green fluourescent protein (GFP) signal. B, Subcellular localization of the GFP control. A patchy fluorescence pattern was observed in about half of the cells. Images are overlays of Nomarski differential interference contrast and GFP images. C, through E, Nuclear localization of IPD3::GFP under control of the $35 \mathrm{~S}$ promoter in root hair of $M$. truncatula. F, through $\mathbf{H}$, Subcellular localization of the GFP control. C and F, red propidium iodide stain showing cell periphery and nuclei. D and G, green GFP signal. E and H, merged image of red and green signals. Scale bars represent $10 \mu \mathrm{m}$. 
(data not shown). By contrast, fusion of GFP to the full-length IPD3 protein resulted in specific accumulation of the fusion protein within the nucleus and significantly reduced signal within the cytoplasm (Fig. 4A). As expected from previous studies (Kalo et al. 2005), N. benthamiana leaves expressing a 35S::DMI3::GFP fusion exhibited a strong nuclear signal (data not shown).

To examine the intracellular distribution of the IPD3::GFP fusion in $M$. truncatula roots, we transformed the same 35S::GFP and chimeric 35S::IPD3::GFP constructs into $M$. truncatula by means of $A$. rhizogenes. Transgenic hairy roots were selected based on red fluorescence conferred by the pRedRoot DsRED1 marker gene. Three-week-old transformed roots were either maintained without inoculation or were inoculated with compatible $S$. meliloti and were scored for GFP localization after 3 days. Similar to the results with $N$. benthamiana, 35S::GFP hairy roots exhibited GFP fluorescence in both the cytoplasmic and nuclear compartments (Fig. 4F through $\mathrm{H}$ ), while $M$. truncatula roots transformed with the IPD3::GFP fusion contained GFP signal specifically within nuclei (Fig. 4D and E). The subcellular location of IPD3::GFP protein was not obviously altered following inoculation with $S$. meliloti (data not shown).

\section{IPD3 interacts with DMI3 and itself in plant nuclei.}

Interestingly, like IPD3, DMI3 has also been localized in the nucleus (Kalo et al. 2005; Smit et al. 2005). To test the interaction of IPD3 and DMI3 proteins in living plant cells, we generated fusions between these two proteins and $\mathrm{N}$-terminal or $\mathrm{C}$ terminal fragments of the enhanced yellow fluorescent protein $\left(\mathrm{YFP}^{\mathrm{N}}\right.$ and $\mathrm{YFP}^{\mathrm{C}}$, respectively). These fusions were transiently expressed in $N$. benthamiana leaves under control of the $35 \mathrm{~S}$ promoter. Expression of $\mathrm{YFP}^{\mathrm{N}}$, YFP ${ }^{\mathrm{C}}$, IPD3::YFP ${ }^{\mathrm{N}}$, IPD3:: $\mathrm{YFP}^{\mathrm{C}}$, DMI3::YFP ${ }^{\mathrm{N}}$, or DMI3::YFP $\mathrm{YP}^{\mathrm{C}}$ individually was not correlated with significant signal in epidermal cells. Coexpression of IPD3::YFP ${ }^{\mathrm{N}}$ with IPD3::YFPC , DMI3:: YFP $^{\mathrm{N}}$ with DMI3::

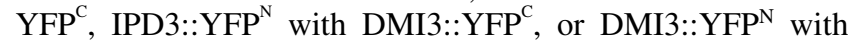
IPD3::YFP ${ }^{C}$ led to a strong nuclear signal in a number of epidermal cells, suggesting interactions of IPD3 with DMI3 and also homomultimerization of IPD3 and DMI3 proteins (Fig. 5A through D). No other combination led to the detection of a significant signal (Fig. 5E).

Artifacts due to the overexpression in nuclei or ectopic expression of these fusions may occur and the homomultimerization of IPD3 and DMI3 still needs to be confirmed through other techniques such as $\mathrm{Y} 2 \mathrm{H}$ or pull-down assays. Nevertheless, given the previous $\mathrm{Y} 2 \mathrm{H}$ and localization results in $M$. truncatula roots, we conclude that IPD3 probably interacts with DMI3 in plant nuclei.

RNA interference in wild-type and $d m i 3$ mutant plants.

To test the possible phenotype of IPD3 during nodulation, RNA interference experiments were carried out on wild-type and TRV25 dmi3 mutant seedlings, using a 400-bp fragment of IPD3 cDNA. Transformed roots were identified based on DsRED1 fluorescence three weeks after inoculation with $S$. meliloti (pXLGD4). As expected, nodules were observed on nontransformed wild-type plants and on wild-type plants transformed with the control pRedRoot::GFP reporter gene. Nodules were also observed on transgenic roots expressing the IPD3RNAi construct. The RNAi-mediated knockdown of IPD3 transcript was confirmed by means of real time PCR (Supplementary Fig. 2). Nodules were never observed on control nontransgenic roots of $d m i 3$ plants nor on $d m i 3$ plants transformed with pRNAiIPD3 or pRedRoot::GFP constructs. Nodule colonization was assessed by means of a $S$. meliloti strain (ABS7M) that constitutively expresses the $\beta$-galactosidase re- porter protein from plasmid pXLGD4. Staining with X-gal substrate revealed efficient rhizobial colonization of both control and IPD3 knockdown roots and similar numbers of nodules between control and knockdown plants. No obvious growth or developmental phenotype was observed in hairy roots transformed with pRNAiIPD3 as compared with roots transformed with the pRedRoot::GFP control.

\section{DISCUSSION}

Here, we report the identification of the IPD3 protein of $M$. truncatula and its interaction with the symbiotic DMI3 CCaMK. Screening of two Y2H libraries of $M$. truncatula cDNAs under stringent conditions identified seven independent clones corresponding to the $3^{\prime}$ region of IPD3 cDNA. Common to all of the $\mathrm{C}$-terminal IPD3 protein products is a
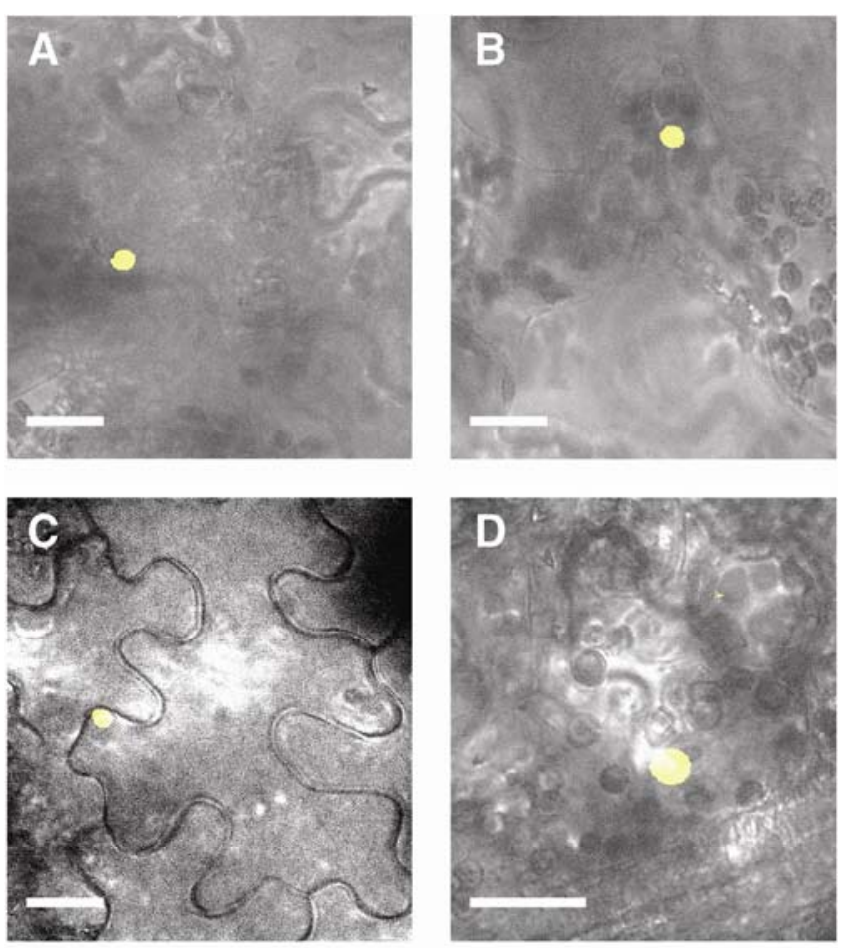

\begin{tabular}{|c|c|c|c|c|}
\hline $\begin{array}{l}\text { DMI3:: } \\
\text { YFPN }\end{array}$ & - & $\mathbf{E}$ & & \\
\hline $\begin{array}{c}\text { DMI3:: } \\
\text { YFPC }^{2}\end{array}$ & + & - & & \\
\hline $\begin{array}{l}\text { IPD3:: } \\
\text { YFPN }^{-1}\end{array}$ & - & + & - & \\
\hline \multirow[t]{2}{*}{$\begin{array}{l}\text { IPD3 :: } \\
\text { YFPC }\end{array}$} & + & - & + & - \\
\hline & $\begin{array}{l}\text { DMI3:: } \\
\text { YFPN }\end{array}$ & $\begin{array}{l}\text { DMI3:: } \\
\text { YFPC }\end{array}$ & $\begin{array}{l}\text { IPD3:: } \\
\text { YFPN }\end{array}$ & $\begin{array}{l}\text { IPD3 }:: \\
\text { YFPC }\end{array}$ \\
\hline
\end{tabular}

Fig. 5. Interaction of IPD3 and DMI3 in Nicotiana benthamiana nuclei. Single transformations of IPD3::YFP ${ }^{\mathrm{N}}$, IPD3::YFPC ${ }^{\mathrm{C}}$, DMI3::YFP ${ }^{\mathrm{N}}$, DMI3:: $\mathrm{YFP}^{\mathrm{C}}$ fusions in $N$. benthamiana leaves did not lead to any significant signal. Cotransformations of fusions with $\mathrm{YFP}^{\mathrm{N}}$ and $\mathrm{YFP}^{\mathrm{C}}$ generated intense nuclear signals in a number of epidermal cells indicating interactions between $\mathbf{A}$, DMI3::YFP ${ }^{\mathrm{N}}$ and IPD3::YFPC, $\mathbf{B}$, DMI3::YFP ${ }^{\mathrm{C}}$ and IPD3::YFP ${ }^{\mathrm{N}}, \mathbf{C}$,

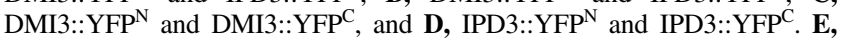
Summary of observations. + indicates an interaction as shown in A to D, and - indicates the absence of YFP signal. Images are overlays of differential interference contrast and YFP images. Scale bars represent $10 \mu \mathrm{m}$. 
canonical coiled-coil structure that may mediate the IPD3DMI3 interaction. Analysis of in vivo protein interaction using the split yellow fluorescent protein (bimolecular fluorescence complementation $[\mathrm{BiFC}]$ ) system suggests that DMI3 and IPD3 interact within nuclei of heterologous $N$. benthamiana cells, consistent with the demonstrated localization of these two proteins within the nucleus (Kalo et al. 2005; this study). Walter and colleagues (2004) conducted similar BiFC experiments involving the bZIP63 nuclear protein and a mutated version named bZIP63 ${ }^{\mathrm{PP}}$ with a reduced dimerization potential. They showed a good correlation between interaction strength measured by $\mathrm{Y} 2 \mathrm{H}$ and signal intensity in BiFC (Walter et al. 2004). Accumulation of weakly interacting bZIP63 ${ }^{\mathrm{PP}}$ proteins in $N$. benthamiana nuclei only led to low-intensity signals. Therefore, it seems reasonable to hypothesize that the intense fluorescent signals that we observed by coexpressing DMI3 and IPD3 fusions result from strong and specific interactions between these proteins. Ultimately, it will be important to verify the proposed protein interactions in nuclei of $M$. truncatula roots by expressing the same fusions under control of the corresponding native promoters.

In addition to a heterologous IPD3-DMI3 interaction, the current BiFC data also suggest interactions of IPD3 and DMI3 proteins in homomeric associations. Consistent with this observation, Sathyanarayanan and colleagues (2001) hypothesized that autophosphorylation of the DMI3 CCaMK ortholog in lily involves an intermolecular mechanism, and they suggest the existence of both oligomeric and multimeric states of CCaMK proteins (Patil et al. 1995; Sathyanarayanan et al. 2001). Given the high conservation of IPD3 and DMI3 proteins among higher plants, it is probable that similar interactions may occur in a range of angiosperms including $N$. benthamiana. We hypothesize that endogenous $N$. benthamiana proteins might facilitate homomeric IPD3 and DMI3 interactions within nuclear protein complexes (Godfroy et al. 2006; Zhu et al. 2006).

If IPD3 functions at or upstream of DMI3, it may regulate DMI3 activity in response to calcium and calmodulin signals. If IPD3 functions downstream of DMI3, it may serve as a substrate for phosphorylation and subsequently interact with transcription factors such as NSP1 or NSP2 or in the negative feedback of DMI3 on calcium spiking (Oldroyd et al. 2001). Alternatively, IPD3 could be a scaffolding protein associated to DMI3. Determining if IPD3 is phosphorylated by DMI3 will help to place IPD3 in the biochemical schematic of symbiotic signaling.

DMI3 is required for rhizobial and AM symbioses in legumes, while the lily CCaMK ortholog to DMI3 has been purified from lily anthers. Although anther-related phenotypes have not been reported for dmi3 mutants, it is possible that DMI3 and IPD3 could play a role in anther development. Nevertheless our expression studies indicate a very low level of expression in flowers compared with roots, suggesting a more likely role of IPD3 in root-related processes. We observed that, under nonsymbiotic conditions, pIPD3::GUS fusions were expressed primarily in the root vasculature. Following inoculation with $S$. meliloti, IPD3 expression was increased in the root cortex prior to nodule formation, while expression was maximal in nodule primordia and in the nitrogen-fixing zone of differentiated nodules. Low but detectable expression was also observed in the nodule preinfection zone. This expression pattern differs from that of other signaling related genes, such as $D M I 1, D M I 2, D M I 3$, and NFP, which are expressed mainly in nodule primordia and in the preinfection zone of mature nodules (Bersoult et al. 2005; Riely et al. 2006, 2007). The observed IPD3 expression pattern is consistent with a role for $I P D 3$ in early signal transduction events and, potentially, also during later steps of symbiosis.
Expression of short hairpin (sh)RNA constructs targeting IPD3 caused a large reduction in IPD3 transcript levels but failed to cause a measurable change in nodule morphogenesis or rhizobial infection. It is possible that IPD3 plays an accessory and not an essential role in nodulation or that residual IPD3 transcript was sufficient to confer wild-type functionality. Alternatively, IPD3 may act at a step in nodulation characterized by functional redundancy. Analysis of the current $M$. truncatula genomic and EST sequence datasets failed to identify paralogs of IPD3, although we cannot rule out the possibility that heterologous protein products confer redundant function. The fact that IPD3 has not been identified in forward genetic screens for nodulation mutants is consistent with IPD3 either acting in an accessory role or at a redundant step. Among the known gene products required for both nodulation and mycorrhization, DMI3 appears to act last in sequence. If IPD3 acts downstream of DMI3, it may be required for the development of arbuscular mycorrhiza. We are currently testing the mycorrhization phenotypes of IPD3 knockdown roots as well as attempting to isolate IPD3 altered-function mutations by means of a TILLING (targeting induced local lesions in genomes) approach. It is also possible that genetic interactions between weak alleles of DMI3 and IPD3 knockdowns may be informative. We have identified three independent TILLING mutants of IPD3 that are viable (J. H. Mun, unpublished data). These mutants must be backcrossed before any in-depth phenotypic characterization.

The widespread phylogenetic distribution and structural conservation of IPD3 from monocots to eudicots is similar to that of DMI3 and is consistent with the presence of homologs of the symbiotic signaling pathway in plants that develop AM associations. Interestingly, the absence of DMI3 and IPD3 in Arabidopsis also correlates with its inability to form AM symbioses. The high conservation of IPD3 protein sequence between $M$. truncatula and rice, especially in the C-terminal region of the protein (a region sufficient for the interaction of MtIPD3 with MtDMI3), suggests that the observed IPD3DMI3 interaction could be conserved across land plants. Characterization of the TILLING mutants may help clarify the role of IPD3 in symbiotic and possibly nonsymbiotic processes.

\section{MATERIALS AND METHODS}

\section{Plant material.}

Seeds of $M$. truncatula lines Jemalong A17, sunn, and skl were scarified in concentrated sulfuric acid for $8 \mathrm{~min}$, were surface-sterilized in $12 \%$ sodium hypochlorite, were imbibed in sterile water, and were plated on $1 \%$ deionized water agar plates. Seeds were subsequently vernalized for $48 \mathrm{~h}$ at $4^{\circ} \mathrm{C}$ and were germinated by incubating at room temperature overnight. All nodulation assays were performed using a suspension of approximately $10^{7} \mathrm{CFU} / \mathrm{ml}$ of $S$. meliloti ABS7M (pXLGD4) and X-gal staining as described previously (Boivin et al. 1990). N. benthamiana plants were grown in a growth chamber at $21^{\circ} \mathrm{C}$ and $16 \mathrm{~h}$ of light.

\section{Y2H libraries and identification of IPD3.}

The nodule-enriched cDNA libraries of A17 (MtY2H1) and sunn/skl (MtY2H2) were constructed using HybriZAP vector from Stratagene (La Jolla, CA, U.S.A.). Total RNA was isolated from the responding zone or nodulated root of $M$. truncatula A17, sunn, and skl 0, 2, 5, and 10 days after inoculation with $S$. meliloti using RNeasy plant mini kit (Qiagen, Valencia, CA, U.S.A.). Poly(A) ${ }^{+}$mRNA was purified from total RNA of A17 or equally pooled total RNA of sunn and $s k l$, using an Oligotex mRNA mini kit (Qiagen). cDNA was synthesized using a HybriZAP-2.1 XR cDNA synthesis kit (Stratagene), was size- 
fractioned to collect cDNAs longer than $0.6 \mathrm{~kb}$, and was then cloned into HybriZAP vector according to the manufacture's direction. Titering of packaged phage demonstrated primary libraries of $>1.5 \times 10^{6}$ PFU. Amplification of 96 plaques revealed $>90 \%$ recombinant phage with an average insert size of $0.9 \mathrm{~kb}$ (range $300 \mathrm{bp}$ to $3 \mathrm{~kb}$ ). The primary library was amplified once and was used for interaction screen.

The HYBRIZAP-2.1 two-hybrid library was converted to a phagemid form, allowing the prey pAD-GAL4 vectors screening in yeast cells, by an efficient in vivo mass excision (Invitrogen, Carlsbad, CA, U.S.A.) of any cDNA insert contained within the lambda vector.

The DMI3 cDNA was inserted in-frame with the GAL4 DNA-BD into the vector pBD-GAL4 containing the TRP1 selectable marker. The screening procedure was followed as recommended by Clontech (MATCHMAKER GAL4 two-hybrid system 3; Palo Alto, CA, U.S.A.). The yeast strain AH109 was sequentially transformed by the bait vector pBD-GAL4::DMI3 and then by the prey vector pAD-GAL4, which contains the LEU2 selectable marker excised from the libraries. A total of 500000 transformants from each library were screened for growth on SD Leu- Trp- His-. His+ positive clones from the first round of screening were confirmed by assaying for a second yeast reporter ADE2 on SD Leu- Trp- His- Ade- media. The positive clones were further confirmed by prey plasmid rescue and retransformation into AH109 with pBDGAL4::DMI3 or with the negative control plasmid (empty pBD-GAL4). Only those growing on SD Leu- Trp- His- Ademedia were further characterized.

\section{Identification of coding and genomic sequences.}

The full-length cDNA sequence of IPD3 was determined using the Smart RACE cDNA amplification kit (Clontech). The BAC clone MtH2_33K20 encoding IPD3 was selected by PCR-based screening of the $4 \times$ DNA pool of MtH2 BAC library. A genomic copy of IPD3 from the BAC clone was amplified using 5'-TAAGTGGAGTCAAAAGAAATAGTTTATA$3^{\prime}$ as a forward primer and 5'-TTTTGCTAATAGACTCCATA GGTTCAC-3' as a reverse primer. The amplified genomic fragment was cloned into pCR2.1-TOPO vector (Invitrogen), and the sequence was determined using series of internal primers.

\section{Genetic mapping of IPD3.}

A single nucleotide polymorphism has been identified by direct sequence comparison between Jemalong A17 and A20 using the primer set $5^{\prime}$-CTTCTGCTGCTGCACCAGTAATCT CAT-3' and 5'-AGCTTGCATATCTGAGGGAATTGTTGG-3'. This marker was mapped on 69 individuals of the F2 population. Information about the mapping population and other markers can be found in the report by Mun and associates (2006). Genetic location and distances expressed in Kosambi centiMorgans have been generated using the Map Manager QTX software (Manly et al. 2001).

\section{Multiple alignment and protein structural analysis.}

Multiple amino-acid sequence alignment was carried out first with ClustalW and manually edited. The HCA (Gaboriaud et al. 1987) was performed to delineate the conserved secondary structural features (strands of $\beta$-sheet and stretches of $\alpha$ helix) along the amino-acid sequence of IPD3 by comparison with the homologous proteins used as a model. HCA plots were generated using the HCA server.

Homology modeling of the C-terminal part of IPD3 was carried out on a Silicon Graphics O2 R10000 workstation, using the programs InsightII, Homology, and Discover3 (Accelrys, San Diego, CA, U.S.A.). According to the percentages of identity $(20 \%)$ and similarity $(57 \%)$ and the HCA plot similarity occurring between the C-terminal part of IPD3 and a hypothetical protein from Staphylococcus aureus (RCSB Protein Data Bank code 2AP3), an accurate three-dimensional model was built for the C-terminal domain of IPD3 from the X-ray coordinates of 2AP3. Steric conflicts were corrected during the model-building procedure, using the rotamer library (Ponder and Richards 1987) and the search algorithm of the Homology program (Mas et al. 1992) to maintain proper side-chain orientation. An energy minimization of the final models was carried out by 250 cycles of steepest descent using Discover3. The program TurboFrodo (Roussel and Cambillau 1989) was run to draw the Ramachandran plot and to perform the superposition of the models. All the residues of the modeled C-terminal domain occurred in the allowed regions of the Ramachandran plot (result not shown). PROCHECK (Laskowski et al. 1993) was used to assess the geometric quality of the three-dimensional models. Calculations performed with ANOLEA (Melo and Feytmans 1998) yielded 21 residues with higher energy (vs. 15 residues for the template protein 2AP3).

Electrostatic potentials were calculated and displayed with GRASP using the parse3 parameters (Nicholls et al. 1991). The solvent probe radius used for molecular surfaces was .14 $\mathrm{nm}$, and a standard .20-nm Stern layer was used to exclude ions from the molecular surface (Gilson and Honig 1987). The inner and outer dielectric constants applied to the protein and the solvent was fixed at 4.0 and 80.0, respectively, and the calculations were performed keeping a salt concentration of 0.145 M. The surface occupied by residues forming the NLS on the molecular surface of the modeled C-terminal domain was calculated with GRASP. Cartoons were drawn with PyMol.

\section{Quantitative reverse transcription (RT)-PCR.}

Quantitative RT-PCR was conducted on RNA isolated from nitrogen-starved uninoculated roots or roots inoculated with 2011 (pXLGD4). cDNA was synthesized from $1 \mu \mathrm{g}$ of total RNA by using the SuperscriptIII first-strand kit (Invitrogen) in a total volume of $20 \mu \mathrm{l}$ with the supplied oligodT primers. Quantitative RT-PCR reactions were performed in triplicate on $3 \mu \mathrm{l}$ of cDNA diluted 10 times by using the SYBR green RTPCR master kit (Qiagen) $\left(40\right.$ cycles at $95^{\circ} \mathrm{C}$ for $30 \mathrm{~s}$ and at $60^{\circ} \mathrm{C}$ for $30 \mathrm{~s}$ ), and real-time detection was performed on a MyIQ PCR machine (BioRad, Hercules, CA, U.S.A.) and was analyzed by using the program GENEX (BioRad). The specificity of the PCR amplification procedures was checked with a heat-dissociation step (from 55 to $95^{\circ} \mathrm{C}$ ) at the end of the run and by agarose gel electrophoresis. Results were standardized to the MtACTIN2 expression levels. The primers used were MtACTIN2, 5'-TGGCATCACTCAGTACCTTTCAACAG-3' and 5'-ACCCAAAGCATCAAATAATAAGTCAACC-3'; IPD3, 5'-GCGCTCAAGAAAAATGGCTGAAGC-3' and 5'-GCTTTA GTGATCGAACTTCCTTCTCAAGG-3'; DMI3， 5'-TCATTG ATCCCTTTTGCTTCTCGT-3' and 5'-GATGCTACTTCCTCT TTGCTGATGC-3'.

\section{RNA interference experiments.}

A 400-bp fragment of the $5^{\prime}$ region of IPD3 was amplified using the primers 5'-CACCATGGAAGGGAGAGGATTTT CTGG-3' and 5'-ATTGCAATTCTCTATCAACAGGATCTC$3^{\prime}$ and was cloned into the pENTR/D vector (Invitrogen). This fragment was then introduced by LR recombination (Invitrogen) in the pK7GWIWG2(II) vector, modified to contain the red fluorescent marker DsRED1 under the control of the constitutive Arabidopsis Ubiquitin 10 promoter and described by Limpens and colleagues (2005). A. rhizogenes MSU440 was used to transform M. truncatula seedlings (Sonti et al. 1995). The binary vector was introduced into MSU440 by electroporation and was grown for 2 days at $28^{\circ} \mathrm{C}$ under spectinomycin 
selection $(50 \mu \mathrm{g} / \mathrm{ml})$. In each experiment, about 60 plants were transformed with each construct and for each plant type as reported previously (Boisson-Dernier et al. 2001). As control for transformation and nodulation efficiency, each plant type was also transformed with the binary vector pRedRoot::GFP (Riely et al. 2007). Plants were inoculated with the $S$. meliloti ABS7M (pXLGD4) strain two weeks after transformation (Boivin et al. 1990).

\section{Construction of chimeric genes and expression in plants.}

For the promoter-GUS fusion, the $1.1-\mathrm{kb}$ promoter region with the $5^{\prime}$ untranslated region was amplified using the primers 5'-TAAGTGGAGTCAAAAGAAATAGTTTATATG-3' and 5'ccatgGAAACACTTGAATGATGCTTGAACTTATT-3' and was cloned into pCR4-TOPO vector (Invitrogen) and then moved into the Pst $\mathrm{I} / N c o$ I site of pCAMBIA3303 binary vector. For the protein-GFP fusion, the IPD3 CDS was amplified without its stop codon, using the primers 5 '-CACCATGGAAG GGAGAGGATTTTCTGG-3' and 5'-ATTCTTTCCAGTTTCT GATAGAATTCT-3', was cloned into the pENTR/D vector (Invitrogen), and was transferred to the pK7FWG2 binary vector by $\mathrm{LR}$ recombination (Invitrogen), resulting in $35 S:: I P D 3:: G F P$ fusion. The GFP fusion under control of a native promoter was made by cloning a 1.1-kb fragment of pIPD3 into the SacI/SpeI site. For the efficient selection in the transformed plant, 35S::DsRED1::oct cassette as a fluorescent selection marker was cloned into the $S a c \mathrm{I} / \mathrm{XbaI}$ site or the ApaI site of pCAMBIA3303 or pK7FWG2, respectively. The chimeric genes were transformed into A. rhizogenes MSU440 to be used for plant transformation. For the transformation of $N$. benthamiana, A. rhizogenes MSU440 was infiltrated along with the A. tumefaciens P19 strain (Voinnet et al. 2003; Witte et al. 2004). Agrobacterium cells in late exponential phase $(<20 \mathrm{~h}$ growth in liquid medium) were harvested by centrifugation and were resuspended in injection buffer containing $10 \mathrm{mM}$ $\mathrm{MgCl}_{2}$ and $100 \mu \mathrm{M}$ acetosyringone) and mixed to an optical density at $600 \mathrm{~nm}$ of 0.1 . Bacteria were injected into young fully expanded leaves of 6-week-old $N$. benthamiana plants. Hairy root transformation of $M$. truncatula and nodulation was performed as described above. Histochemical analysis of GUS activity was performed as described by Mun and associates (2002). Transformed roots were incubated in GUS staining solution containing $0.1 \mathrm{M}$ sodium phosphate buffer, $\mathrm{pH}$ 7.0, $0.1 \%$ Triton $\mathrm{X}-100,10 \mathrm{mM}$ EDTA, $0.5 \mathrm{mM} \mathrm{K}_{3} \mathrm{Fe}(\mathrm{CN})_{6}, 0.5$ $\mathrm{mM} \mathrm{K}{ }_{4} \mathrm{Fe}(\mathrm{CN})_{6}$ and $1 \mathrm{mM} \mathrm{X-Gluc}$ at $37^{\circ} \mathrm{C}$ for $24 \mathrm{~h}$ because of low activity. To make sections, stained whole roots or nodules were fixed in $2 \%$ paraformaldehyde and were embedded into $3 \%$ agarose, and sliced into 100 - to $120-\mu \mathrm{m}$-thick sections, using vibratome. Photographs were taken using a differential interference contrast (DIC) or stereomicroscope in dark-field. The localization of GFP-fused proteins in transformed leaves or roots were observed from 3 to 6 days postinfiltration of $N$. benthamiana or 2 weeks after Agrobacterium coculture of $M$. truncatula, using a BioRad MRC 1024 confocal microscope with staining of DAPI and propidium iodide.

\section{BiFC experiments.}

The DMI3 CDS was amplified without its stop codon using the primers 5'-CACCATGGGATATGGAACAAGAAAACTC$3^{\prime}$ and: 5'-TGGACGAATAGAAGAGAGAACTACATC-3', cloned into the $\mathrm{pENTR/D}$ vector (Invitrogen). The CDS of DMI3 and IPD3 without stop codons have been transferred to the pSPYNE-35SGW and pSPYCE-35SGW vectors by LR recombination (Invitrogen). We created GATEWAY-compatible vectors by transferring a GATEWAY-conversion cassette $(r f \mathrm{~B})$ that was EcoRV-inserted into pBSKII+, into pSPYNE-35S, and pSPYCE-35S (Walter et al. 2004), respectively, using an
$X b a I$ and $X h o I$ digest and ligation to obtain pSPYNE-35SGW $\left(\right.$ gene:YFP ${ }^{\mathrm{N}}$ ) and pSPYNE-35SGW (gene:YFPC). All combinations have been generated and coexpressed in $N$. benthamiana leaves as described previously.

\section{ACKNOWLEDGMENTS}

This work was supported by the United States Department of Agriculture (USDA-CSREES grant number 05-562-35319). E. Messinese and G. Lougnon were funded by the French Ministère de l'Enseignement Supérieur et de la Recherche. Confocal microscopy was performed at the University of Wisconsin-Madison Plant Imaging Center and was supported by the National Science Foundation (DBI-0421266).

\section{LITERATURE CITED}

Akiyama, K., Matsuzaki, K., and Hayashi, H. 2005. Plant sesquiterpenes induce hyphal branching in arbuscular mycorrhizal fungi. Nature 435:824-827.

Ané, J. M., Kiss, G. B., Riely, B. K., Penmetsa, R. V., Oldroyd, G. E., Ayax, C., Lévy, J., Debellé, F., Baek, J. M., Kalo, P., Rosenberg, C., Roe, B. A., Long, S. R., Dénarié, J., and Cook, D. R. 2004. Medicago truncatula DMI1 required for bacterial and fungal symbioses in legumes. Science 303:1364-1367.

Arrighi, J.-F., Barre, A., Ben Amor, B., Bersoult, A., Soriano, L. C. Mirabella, R., de Carvalho-Niebel, F., Journet, E.-P., Ghérardi, M., Huguet, T., Geurts, R., Dénarié, J., Rouge, P., and Gough, C. 2006. The Medicago truncatula LysM-receptor kinase gene family includes NFP and new nodule-expressed genes. Plant Physiol. pp.106.084657. Published online.

Bersoult, A., Camut, S., Perhald, A., Kereszt, A., Kiss, G. B., and Cullimore, J. V. 2005. Expression of the Medicago truncatula DMI2 gene suggests roles of the symbiotic nodulation receptor kinase in nodules and during early nodule development. Mol. Plant-Microbe Interact. 18:869-876.

Boisson-Dernier, A., Chabaud, M., Garcia, F., Bécard, G., Rosenberg, C., and Barker, D. G. 2001. Agrobacterium rhizogenes-transformed roots of Medicago truncatula for the study of nitrogen-fixing and endomycorrhizal symbiotic associations. Mol. Plant-Microbe Interact. 14:695700.

Boivin, C., Camut, S., Malpica, C. A., Truchet, G., and Rosenberg, C. 1990. Rhizobium meliloti genes encoding catabolism of trigonelline are induced under symbiotic conditions. Plant Cell 2:1157-1170.

Dénarié, J., Debellé, F., and Promé, J. C. 1996. Rhizobium lipo-chitooligosaccharide nodulation factors: Signaling molecules mediating recognition and morphogenesis. Annu. Rev. Biochem. 65:503-535.

Endre, G., Kereszt, A., Kevei, Z., Mihacea, S., Kalo, P., and Kiss, G. B. 2002. A receptor kinase gene regulating symbiotic nodule development. Nature 417:962-966.

Gaboriaud, C., Bissery, V., Benchetrit, T., and Mornon, J. P. 1987. Hydrophobic cluster analysis: An efficient new way to compare and analyze amino-acid sequences. FEBS (Fed. Eur. Biochem. Soc.) Lett. 224:149155.

Gilson, M. K., and Honig, B. H. 1987. Calculation of electrostatic potentials in an enzyme active site. Nature 330:84-86.

Gleason, C., Chaudhuri, S., Yang, T., Munoz, A., Poovaiah, B. W., and Oldroyd, G. E. D. 2006. Nodulation independent of rhizobia induced by a calcium-activated kinase lacking autoinhibition. Nature 441:1149-1152.

Godfroy, O., Debellé, F., Timmers, T., and Rosenberg, C. 2006. A rice calcium- and calmodulin-dependent protein kinase restores nodulation to a legume mutant. Mol. Plant-Microbe Interact. 19:495-501.

Harrier, L. A. 2001. The arbuscular mycorrhizal symbiosis: A molecular review of the fungal dimension. J. Exp. Bot. 52:469-478.

Imaizumi-Anraku, H., Takeda, N., Charpentier, M., Perry, J., Miwa, H., Umehara, Y., Kouchi, H., Murakami, Y., Mulder, L., Vickers, K., Pike, J., Allan Downie, J., Wang, T., Sato, S., Asamizu, E., Tabata, S., Yoshikawa, M., Murooka, Y., Wu, G. J., Kawaguchi, M., Kawasaki, S., Parniske, M., and Hayashi, M. 2005. Plastid proteins crucial for symbiotic fungal and bacterial entry into plant roots. Nature 433:527-531.

Kalo, P., Gleason, C., Edwards, A., Marsh, J., Mitra, R. M., Hirsch, S., Jakab, J., Sims, S., Long, S. R., Rogers, J., Kiss, G. B., Downie, J. A., and Oldroyd, G. E. 2005. Nodulation signaling in legumes requires NSP2, a member of the GRAS family of transcriptional regulators. Science 308:1786-1789.

Kosuta, S., Chabaud, M., Lougnon, G., Gough, C., Dénarié, J., Barker, D. G., and Bécard, G. 2003. A diffusible factor from arbuscular mycorrhizal fungi induces symbiosis-specific MtENOD11 expression in roots of Medicago truncatula. Plant Physiol. 131:952-962. 
Laskowski, R. A., Macarthur, M. W., Moss, D. S., and Thornton, J. M. 1993. PROCHECK - A program to check the stereochemical quality of protein structures. J. Appl. Crystallogr. 26:283-291.

Lévy, J., Bres, C., Geurts, R., Chalhoub, B., Kulikova, O., Duc, G., Journet, E. P., Ané, J. M., Lauber, E., Bisseling, T., Dénarié, J., Rosenberg, C., and Debellé, F. 2004. A putative $\mathrm{Ca}^{2+}$ and calmodulin-dependent protein kinase required for bacterial and fungal symbioses. Science 303:13611364.

Limpens, E., Franken, C., Smit, P., Willemse, J., Bisseling, T., and Geurts, R. 2003. LysM domain receptor kinases regulating rhizobial Nod factor-induced infection. Science 302:630-633.

Limpens, E., Mirabella, R., Fedorova, E., Franken, C., Franssen, H., Bisseling, T., and Geurts, R. 2005. Formation of organelle-like $\mathrm{N}_{2}$-fixing symbiosomes in legume root nodules is controlled by DMI2. Proc. Natl. Acad. Sci. U.S.A. 102:10375-10380.

Long, S. R. 1996. Rhizobium symbiosis: Nod factors in perspective. Plant Cell 8:1885-1898.

Madsen, E. B., Madsen, L. H., Radutoiu, S., Olbryt, M., Rakwalska, M., Szczyglowski, K., Sato, S., Kaneko, T., Tabata, S., Sandal, N., and Stougaard, J. 2003. A receptor kinase gene of the LysM type is involved in legume perception of rhizobial signals. Nature 425:637-640.

Manly, K. F., Cudmore, R. H., and Meer, J. M. 2001. Map manager QTX, cross-platform software for genetic mapping. Mamm. Genome 12:930932.

Mas, M. T., Smith, K. C., Yarmush, D. L., Aisaka, K., and Fine, R. M. 1992. Modeling the anti-CEA antibody combining site by homology and conformational search. Proteins 14:483-498.

Melo, F., and Feytmans, E. 1998. Assessing protein structures with a nonlocal atomic interaction energy. J. Mol. Biol. 277:1141-1152.

Mitra, R. M., Gleason, C. A., Edwards, A., Hadfield, J., Downie, J. A., Oldroyd, G. E., and Long, S. R. 2004. A $\mathrm{Ca}^{2+}$ dependent protein kinase required for symbiotic nodule development: Gene identification by transcript-based cloning. Proc. Natl. Acad. Sci. U.S.A. 101:4701-4705.

Mulder, L., Lefebvre, B., Cullimore, J., and Imberty, A. 2006. LysM domains of Medicago truncatula NFP protein involved in Nod factor perception. Glycosylation state, molecular modeling and docking of chitooligosaccharides and Nod factors. Glycobiology doi:10.1093/glycob/cwl006.

Mun, J. H., Lee, S. Y., Yu, H. J., Jeong, Y. M., Shin, M. Y., Kim, H., Lee, I., and Kim, S. G. 2002. Petunia actin-depolymerizing factor is mainly accumulated in vascular tissue and its gene expression is enhanced by the first intron. Gene 292:233-243.

Mun, J. H., Kim, D. J., Choi, H. K., Gish, J., Debellé, F., Mudge, J., Denny, R., Endre, G., Saurat, O., Dudez, A. M., Kiss, G. B., Roe, B., Young, N. D., and Cook, D. R. 2006. Distribution of microsatellites in the genome of Medicago truncatula: A resource of genetic markers that integrate genetic and physical maps. Genetics 172:2541-2555.

Mylona, P., Pawlowski, K., and Bisseling, T. 1995. Symbiotic nitrogenfixation. Plant Cell 7:869-885.

Newsham, K. K., Fitter, A. H., and Watkinson, A. R. 1995. Multi-functionality and biodiversity in arbuscular mycorrhizas. Trends Ecol. Evol. 10:407-411.

Nicholls, A., Sharp, K. A., and Honig, B. 1991. Protein folding and association-Insights from the interfacial and thermodynamic properties of hydrocarbons. Proteins 11:281-296.

Olah, B., Brière, C., Bécard, G., Dénarié, J., and Gough, C. 2005. Nod factors and a diffusible factor from arbuscular mycorrhizal fungi stimulate lateral root formation in Medicago truncatula via the DMII/DMI2 signalling pathway. Plant J. 44:195-207.

Oldroyd, G. E. D., and Downie, J. A. 2006. Nuclear calcium changes at the core of symbiosis signalling, Curr. Opin. Plant Biol. 9:351-357.

Oldroyd, G. E., Mitra, R. M., Wais, R. J., and Long, S. R. 2001. Evidence for structurally specific negative feedback in the Nod factor signal transduction pathway. Plant J. 28:191-199.

Patil, S., Takezawa, D., and Poovaiah, B. W. 1995. Chimeric plant calcium/ calmodulin-dependent protein kinase gene with a neural visinin-like calcium-binding domain. Proc. Natl. Acad. Sci. U.S.A. 92:4897-4901.

Penmetsa, R. V., and Cook, D. R. 1997. A legume ethylene-insensitive mutant hyperinfected by its rhizobial symbiont. Science 275:527-530.

Penmetsa, R. V., Frugoli, J. A., Smith, L. S., Long, S. R., and Cook, D. R. 2003. Dual genetic pathways controlling nodule number in Medicago truncatula. Plant Physiol. 131:998-1008.

Ponder, J. W., and Richards, F. M. 1987. Tertiary templates for proteinsUse of packing criteria in the enumeration of allowed sequences for different structural classes. J. Mol. Biol. 193:775-791.

Radutoiu, S., Madsen, L. H., Madsen, E. B., Felle, H. H., Umehara, Y., Gronlund, M., Sato, S., Nakamura, Y., Tabata, S., Sandal, N., and Stougaard, J. 2003. Plant recognition of symbiotic bacteria requires two LysM receptor-like kinases. Nature 425:585-592.

Riely, B. K., Mun, J. H., and Ané, J. M. 2006. Unraveling the molecular basis for symbiotic signal transduction in legumes. Mol. Plant Pathol. 7:197-207.

Riely, B. K., Lougnon, G., Ané, J. M., and Cook, D. R. 2007. The symbiotic ion channel homolog DMI1 functions in the nuclear membrane of Medicago truncatula roots. Plant J. 49:208-216.

Roussel, A., and Cambillau, C. 1989. TURBO-FRODO. S. G. Silicon Graphics Geometry Partners Directory. Silicon Graphics, Mountain View, CA, U.S.A.

Sathyanarayanan, P. V., Siems, W. F., Jones, J. P., and Poovaiah, B. W. 2001. Calcium-stimulated autophosphorylation site of plant chimeric calcium/calmodulin-dependent protein kinase. J. Biol. Chem. 276:32940-32947.

Schützendübel, A., and Polle, A. 2002. Plant responses to abiotic stresses: Heavy metal-induced oxidative stress and protection by mycorrhization. J. Exp. Bot. 53:1351-1365.

Smit, P., Raedts, J., Portyanko, V., Debellé, F., Gough, C., Bisseling, T., and Geurts, R. 2005. NSP1 of the GRAS protein family is essential for rhizobial Nod factor-induced transcription. Science 308:1789-1791.

Sonti, R. V., Chiurazzi, M., Wong, D., Davies, C. S., Harlow, G. R. Mount, D. W., and Signer, E. R. 1995. Arabidopsis mutants deficient in T-DNA integration. Proc. Natl. Acad. Sci. U.S.A. 92:11786-11790.

Spaink, H. P. 2004. Specific recognition of bacteria by plant LysM domain receptor kinases. Trends Microbiol. 12:201-204.

Stacey, G., Libault, M., Brechenmacher, L., Wan, J., and May, G. D. 2006. Genetics and functional genomics of legume nodulation. Curr Opin Plant Biol. 9:110-121.

Stracke, S., Kistner, C., Yoshida, S., Mulder, L., Sato, S., Kaneko, T., Tabata, S., Sandal, N., Stougaard, J., Szczyglowski, K., and Parniske, M. 2002. A plant receptor-like kinase required for both bacterial and fungal symbiosis. Nature 417:959-962.

Tirichine, L., Imaizumi-Anraku, H., Yoshida, S., Murakami, Y., Madsen, L. H., Miwa, H., Nakagawa, T., Sandal, N., Albrektsen, A. S., Kawaguchi, M., Downie, A., Sato, S., Tabata, S., Kouchi, H., Parniske, M., Kawasaki, S., and Stougaard, J. 2006. Deregulation of a $\mathrm{Ca}^{2+} /$ calmodulin-dependent kinase leads to spontaneous nodule development. Nature 441:1153-1156.

Voinnet, O., Rivas, S., Mestre, P., and Baulcombe, D. 2003. An enhanced transient expression system in plants based on suppression of gene silencing by the p19 protein of tomato bushy stunt virus. Plant J. 33:949956.

Walter, M., Chaban, C., Schutze, K., Batistic, O., Weckermann, K., Nake, C., Blazevic, D., Grefen, C., Schumacher, K., Oecking, C., Harter, K., and Kudla, J. 2004. Visualization of protein interactions in living plant cells using bimolecular fluorescence complementation. Plant J. 40:428-438.

Wang, W., and Poovaiah, B. W. 1999. Interaction of plant chimeric calcium/ calmodulin-dependent protein kinase with a homolog of eukaryotic elongation factor-1alpha. J. Biol. Chem. 274:12001-12008.

Witte, C. P., Noel, L. D., Gielbert, J., Parker, J. E., and Romeis, T. 2004 Rapid one-step protein purification from plant material using the eightamino acid StrepII epitope. Plant Mol. Biol. 55:135-147.

Zhu, H. Y., Riely, B. K., Burns, N. J., and Ané, J. M. 2006. Tracing nonlegume orthologs of legume genes required for nodulation and arbuscular mycorrhizal symbioses. Genetics 172:2491-2499.

\section{AUTHOR-RECOMMENDED INTERNET RESOURCES}

EMBnet COILS server: www.ch.embnet.org/software/COILS_form.html The GeneIndex project: www.tigr.org/tdb/tgi/mtgi The HCA server: www.lmcp.jussieu.fr

MyHits protein motif search: myhits.isb-sib.ch/cgi-bin/motif_scan Delano Scientific PyMol website: www.delanoscientific.com 